\title{
Research on comprehensive evaluation of Payment for ecological services effect of environmental pollution loss in Industrial Park
}

\section{CURRENT STATUS: POSTED}

Research Square

\section{Xiuyan Han}

Nanjing University of Aeronautics and Astronautics

$\checkmark$ njuptxiuyanhan@163.comCorresponding Author

ORCiD: https://orcid.org/0000-0003-2088-2066

\section{Tianyi Cao}

Dalian University of Technology

\section{DOI:}

$10.21203 / \mathrm{rs} .2 .22730 / \mathrm{v} 1$

\section{SUBJECT AREAS}

Environmental Policy

\section{KEYWORDS}

Payment for ecological services effect, comprehensive evaluation, space niche suitability model, environmental pollution loss, industrial park 
Abstract

Background: China's industrial parks are the main force of economic development $\square$ payment for ecological services $\square \mathrm{PES} \square$ effect of environmental pollution loss in industrial parks is significant for sustainable development of industrial parks. In order to explore effective method of Payment for ecological services effect evaluation $\square$ ECEE $\square$ of the environmental pollution loss $\square$ EPL $\square$ in industrial parks, based on literature review and current situation analysis, 24 evaluation indicators of four kinds were selected to build the evaluation indicator system. According to requirements of Payment for ecological services effect evaluation of environmental pollution loss in industrial parks, niche suitability model (NFM) is introduced, based on analysis and improvement of which, spatial niche suitability model (SNSM) is constructed. Then, the application test of SNSM is carried out using related research data, taking Nanjing MV Industrial Park as an example. Results: The evaluation results show that the Payment for ecological services effect of environmental pollution loss in Nanjing MV industrial park shows an upward trend from 2011 to 2018, but the upward situation is imbalanced, and effect improvement of ecological environment compensation inputs and ecological environmental pollution is obviously lagging behind, and still the future work focus of Nanjing MV Industrial Park. Conclusions: Through comparative analysis, it is shown that the evaluation results of spatial niche suitability model are more in line with the actual situation of Nanjing MV Industrial Park, and this method is more suitable for the comprehensive evaluation of Payment for ecological services effect of environmental pollution loss. The research results of this paper provide an effective quantitative analysis method for Payment for ecological services effect management and prevention of Payment for ecological services risks of industrial parks.

\section{Full Text}

Due to technical limitations, full-text HTML conversion of this manuscript could not be completed. However, the manuscript can be downloaded and accessed as a PDF. Figures 


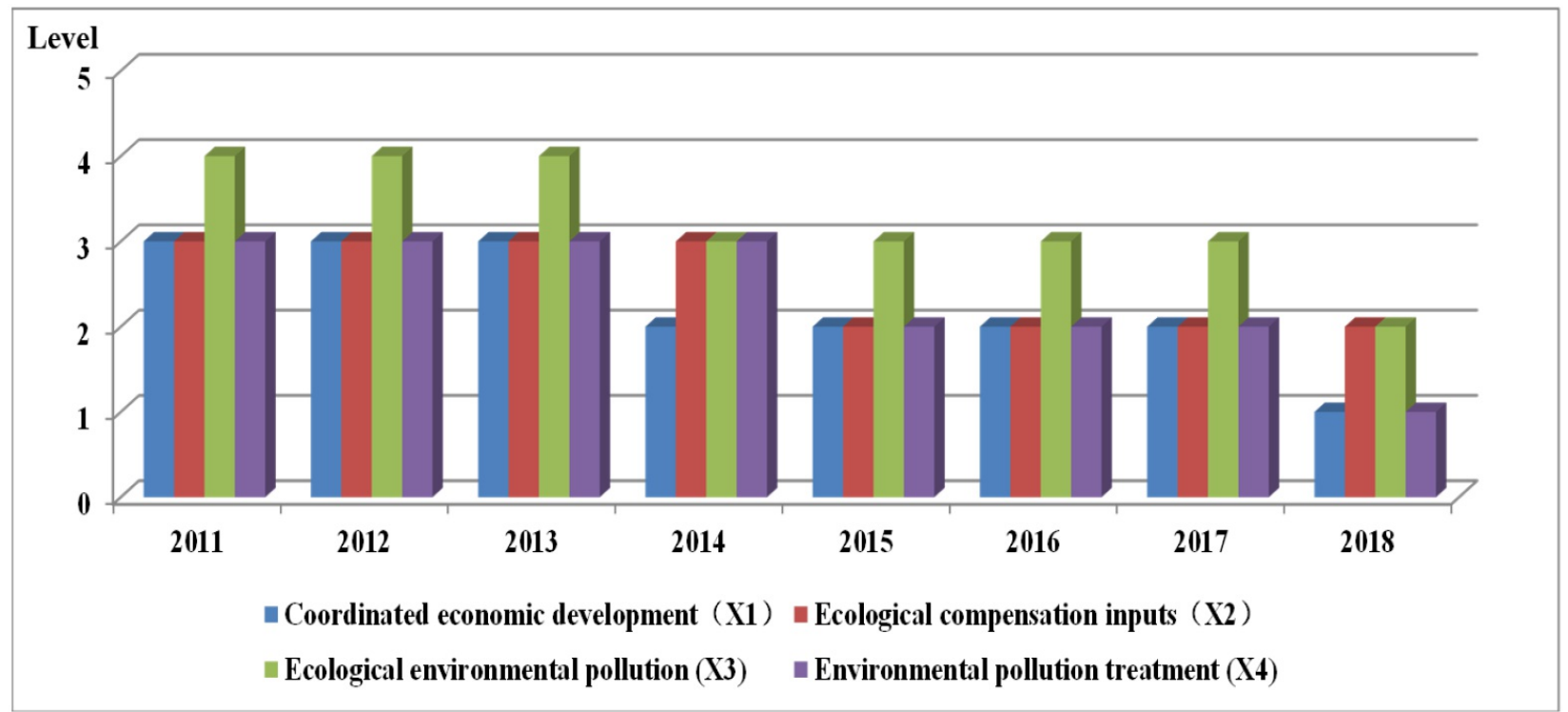

Figure 1

Change rule and interrelation diagram of evaluation grade of ECE of EPL in Nanjing MV Industrial Park

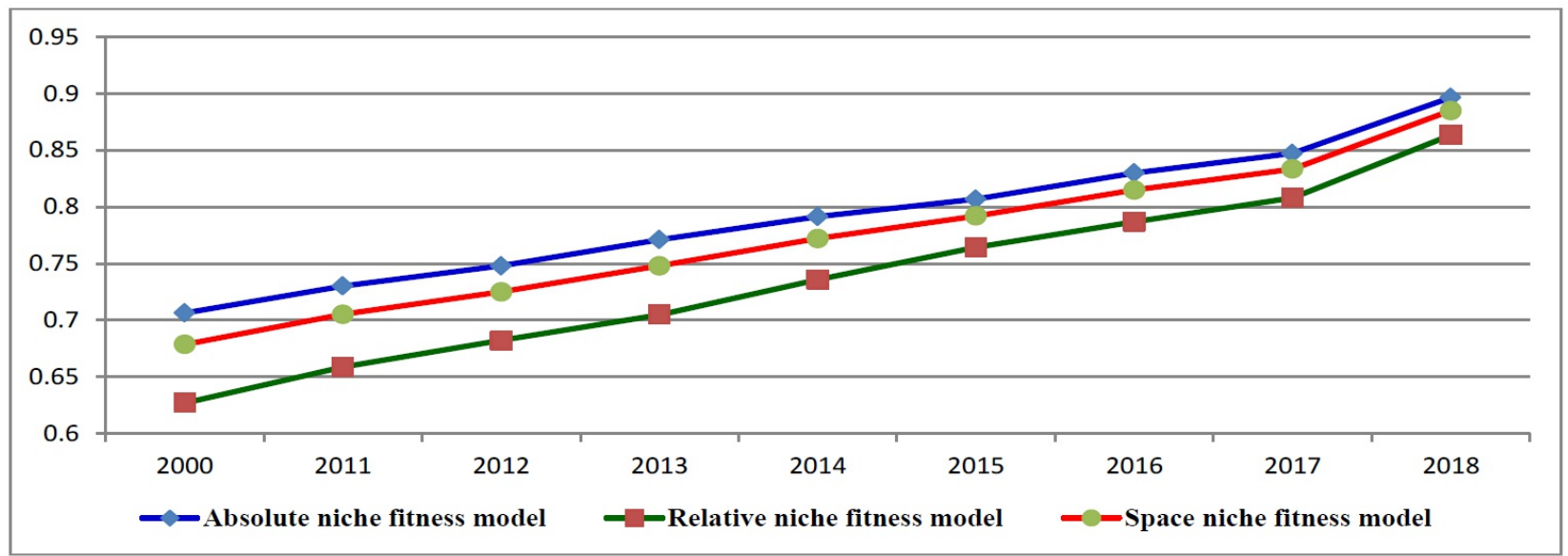

Figure 2

Change trend and interrelation chart of evaluation results of different evaluation models

\section{Supplementary Files}

This is a list of supplementary files associated with this preprint. Click to download.

Graphical Abstract.pdf

Highlights.pdf 